\title{
Communicating health impact of air pollution
}

\author{
Moshammer Hanns for the Aphekom team ${ }^{1}$ \\ Inst. Environmental Health, ZPH, Medical University of Vienna \\ Austria
}

\section{Introduction}

Adverse health effects of air pollution are well established mostly through epidemiological studies, although also toxicology is consistently accumulating findings as to the underlying mechanisms of these effects. Mostly, it seems, these mechanisms are not very specific: inflammatory processes and oxidative stress predominate. Some pollutants also have mutagenic properties making cancer also a plausible health endpoint of exposure to air pollution. But the long lags between exposure and final disease make epidemiological studies in this field very difficult, so direct epidemiological evidence for cancer effects of air pollution is rare. Nevertheless the few existing studies give a consistent and plausible picture. More importantly there are studies that rather than looking at ultimate disease investigate biological effects that might lead to cancer like DNA adducts or chromosome damage. So even for cancer epidemiological evidence is growing.

Several reviews have described the health effects of air pollution in more detail, namely reports by the World Health Organization (WHO 2000; 2005; 2006; 2007) and by the Health Effects Institute (HEI 2000; 2003; 2007; 2010). This chapter will not repeat these valuable and extensive summaries but is rather interested in the link between the scientific findings and policy implications. In fact policies do not deal with air pollution per se, but with specific sources of air pollution thus affecting the interests of several influential stakeholders. So from a policy perspective science is not only called to estimate the health effect of 'air pollution in general' but the health effects linked to a specific source of air pollution or more precisely a specific incremental change in pollutants production by that specific source.

Air pollution always consists of a whole range of pollutants, gaseous and particulate alike. Keeping in mind the little specificity of the air pollutants' toxicity it is not surprising that not one single pollutant alone accounts for the observed effects. Routine monitoring of air quality is usually restricted to some very few indicators (particulate mass and some gases like ozone, nitrogen oxides, sulphur oxide, and carbon monoxide). Simply because of data availability most epidemiological studies describe the association between those indicator pollutants and health risks. But that does not mean that other usually unmeasured pollutants (polycyclic aromatic hydrocarbons, volatile organic compounds, aldehydes, to name but a few) are not similarly relevant in terms of health effects. Particle mass itself is an indicator covering a whole range of particles differing in size, shape and chemical

\footnotetext{
${ }^{1}$ www.aphekom.org
} 
composition. Although the routine indicators of air quality have been shown to be generally good indicators of the overall air quality it cannot be expected that their health relevance is the same no matter what their very source is: particles from incineration processes (e.g. exhaust pipes of motor cars or industrial stacks) are certainly different from particles stemming from desert storms or from sea salt spray.

So policy is required not just to do some 'indicator variable cosmetic' but tackle those sources with the largest health relevance. Ideally it would not only be health effects of air pollutants that are mitigated by a successful policy. Take road traffic as an example: A successful policy would not only reduce air pollution but also noise, $\mathrm{CO}_{2}$ and risk of accidents.

Thus source-specific effects of air pollution are one issue when science meets policy. Another equally challenging issue is the communication of scientific findings. Both health effects of air pollution and the costs of reducing air pollution are very emotional issues and science is not suited well to deal with emotions. Making things worse the talk is about 'risk' and the understanding of that word differs a lot between lay and scientific language. For a scientist 'risk' has a purely statistical meaning while a lay person is more interested in individual risk. In that case the term would include fear which is not so much associated with the statistical likelihood of an event but with (inter alia) its strangeness and severity. A 'good story' making an event more plausible in individual terms might make a risk more relevant while a perception of own control (even if misguided) will reduce the fear and thus the feeling of risk.

Even more importantly epidemiologists tend to talk about relative risks, and small relative risks indeed in the case of air pollution: Since everybody is exposed to air pollution to some extent it is not possible to describe the risk of exposure relative to non-exposure, but usually the relative risk of an incremental increase of exposure is given. Considering reasonable increases in exposure (e.g. per $10 \mu \mathrm{g} / \mathrm{m}^{3}$ of fine particles, PM2.5) the incidence of some health effects might increase by a few percent or even less (depending on the averaging time of the exposure under study). For rare diseases increase in incidence (or prevalence) by a few percent is by no means much. An individual should not be deeply concerned about these additional risks, not only because these risks are small, but also because (s)he usually cannot do anything about it personally. So it might be seen as common logic that risks of that kind are usually disregarded by the general public. Nevertheless for the whole population even relatively rare diseases translate into a certain number of patients and any additional patient is an additional burden to society and the health care system, not to speak about individual hardships. These individual patients will never be proved to be caused by air pollution. The unspecific nature of the pollutants' effects makes it impossible to discern the individual causes. Nevertheless there are a number of additional cases of disease and death that could have been prevented but for the totally involuntary exposure to air pollution. Since practically everybody is exposed to air pollution also small relative risks translate into a surprisingly large number of additional 'cases'.

So science faces the task to explain small individual risks that still are relevant for society. Ideally this explanation should not end at 'air pollution per se' but should strive to discern different sources of air pollution. The latter is not only difficult because of the complex mixture of pollutants originating from each individual source but also because there is a long way from the pollution source to the population exposure where not only the chemical composition of the pollution mixture at the source must be considered but also chemical fate and distribution on its way to the noses of the people. This indeed calls for some interdisciplinary efforts. 


\section{The concepts of causality}

Aristotle discerned four kinds of causes, where his term of "cause" (Greek aitia) had a broader meaning than today's "cause": Thus "causa materialis" and "causa formalis" describe a thing (by its material substance and its form) while the latter two "causes" are more in line with the modern meaning. It seems noteworthy that only the "causa efficiens" resembles the modern concept of a cause preceding the effect ("poster hoc ergo propter hoc") while the concept of "causa finalis" is usually not used in natural sciences. Nevertheless in social sciences it is well established that also goals (i.e. intended future events) strongly influence current events. Life sciences are positioned in the grey zone between natural and social sciences. Therefore it is not surprising that biological mechanisms could be described either by the concept of "causa efficiens" or of "causa finalis". While it is just and common belief that each process in life has at least one preceding cause because of the complexity of most causal chains and networks it is often more straightforward and easier to understand and memorise mechanisms that are described in relation to their intended goal. For example inflammation could be explained by describing all the cytokines and mediating substances involved or it could be described as a mechanism shaped to clean the organism from unwanted material like microbes or noxious chemicals. The latter explanation makes it easier to understand the importance but also the possible harmful effects of such a process. Often this is more relevant for an understanding that can inform reasonable intervention. Nevertheless in this paper "cause" is understood in its natural science meaning.

In formal logics simple causal chains can be constructed like "A causes B, B causes C, etc." but in real world settings causality is often more complex like "A, B, and C cause D which in turn causes $\mathrm{E}$ and $\mathrm{F}$ and prevents $\mathrm{G}$ and $\mathrm{H}$ which again in turn exact an influence on $\mathrm{A}, \mathrm{B}$ or $C "$. Thus we might have complex positive or negative feedback loops and often we even have no means to know or monitor the true underlying causes of an event but are restricted to proxy data that are only somehow related to or associated with the truly causal factor. In theory natural scientists formulate hypotheses that can be falsified. But at least in the complex world of life sciences neither "proof" nor falsification are easy tasks. More often collected data only can render hypotheses more or less plausible. As a consequence "causality" in life sciences tends to be a fuzzier term than in physics.

In their very enlightening book Rifkin \& Bouwer (2008) propose the "Risk Characterisation Theatre" to illustrate risks. "If there were 1,000 people sitting in a theatre with significantly elevated cholesterol levels of $280 \mathrm{mg}$, there will be one additional death per year from coronary heart disease as compared to 1,000 people with normal cholesterol." Even more impressive is their example concerning benefits of colorectal cancer screening: "If there were 1,000 people sitting in a theatre who had colorectal cancer screening, there will be one cancer prevented over a life time as compared to 1,000 people not screened." This statement is striking considering modern theatre: were people seated there over a life time they would rather die of boredom than of colon cancer.

Apart from these entertaining examples clearly indicating that absolute risks are more relevant and meaningful to us than relative risks the authors also introduce a second term in addition to "cause". In chapter two they set out to explain the differences between "cause and effect" versus "risk factors" but in my mind they completely fail to succeed. Their first example for a "risk factor" is a "lump in the breast detected in a mammogram". This they declare to be a "risk factor" (and evidently not a cause) for breast cancer. "There is no cause and effect relationship because the presence of a lump is not always associated with cancer." 
Now this is interesting! Following this line of argumentation smoking would not be causally linked with lung cancer because it does not always lead to that outcome. Or even shooting a person would not be causally linked to his or her death because a bullet not always leads to it. While I agree that a "lump in the breast" is not the cause of breast cancer (rather the other way round!) I also do not consider a lump as a risk factor, only as a symptom! In fact the authors are not very clear regarding their distinction between "cause" and "risk factor". Maybe they just have the feeling that a "cause" is a rather strong risk factor. But since they question the validity of relative risks and do not give a threshold in terms of absolute risks to discern between "cause" and "risk factor" their terminology remains obscure. Sometimes it seems they understand by "cause" an event that practically always leads to an effect but even for the examples they give this is usually not the case. Alternatively they might mean by "cause" an event that practically always precedes an effect. The typical example would be infectious diseases: Tuberculosis is always caused by mycobacteria. But in fact this statement is rather a tautology because tuberculosis is defined as being caused by mycobyacteria. Tuberculosis can take many forms from acute to chronic pneumonia, inflammation of practically every body part, silent knot or scar in the lung tissue, caverns in the lung or septicaemic disease. Often only when we detect mycobacteria (or at least an immune response against these bacteria) do we diagnose tuberculosis. Pneumonia is not always caused by mycobacteria and mycobacteria not always cause pneumonia. In fact many people have been exposed to mycobacteria and only few of them have developed any kind of disease at all.

The so-called Koch's postulates ${ }^{2}$ that were first proposed by Henle and then by Koch (1884) but coined as a term by Koch's pupil Loeffler are often seen as criteria of causality (Evans, 1976) and even are revoked with new emerging concepts of infectious disease (Walker et al., 2006; Falkow, 1988). But even Koch himself was aware that these were rather a description of the microbiology methods of his times and no criteria of causation. The misconception of the postulates stipulating causation indeed hindered for some time the wide acceptance of viruses as infectious agents.

Looking at the postulates without prejudice rather provokes the idea that microbiology lacks good proofs of causality at least regarding individual cases. The only fact the postulates help to establish is the ability, not the necessity of any bacterial strain to cause a certain disease.

Unfortunately with environmental epidemiology the situation is not much better (Kundi, 2006). Here the so-called "Bradford-Hill criteria" 3 are widely supposed to indicate causation.

2 Koch's postulates are:

1. The microorganism must be found in abundance in all organisms suffering from the disease, but should not be found in healthy animals.

2. The microorganism must be isolated from a diseased organism and grown in pure culture.

3. The cultured microorganism should cause disease when introduced into a healthy organism.

4. The microorganism must be reisolated from the inoculated, diseased experimental host and identified as being identical to the original specific causative agent.

3 Hill's criteria are:

1. Strength: A small association does not mean that there is not a causal effect.

2. Consistency: Consistent findings observed by different persons in different places with different samples strengthen the likelihood of an effect. 
Just by calling them "criteria" makes them seem like a "check-list" (Phillips and Goodman, 2004), but this was not Bradford Hill's intention. In his seminal presentation (1965) he explicitly stated: "None of my nine viewpoints can bring indisputable evidence for or against the cause-and-effect hypothesis and none can be required sine qua non".

Comparing infectious with "environmental" diseases (like those caused by air pollution) is not so far fetched. In fact it is known that only rarely a single bacterium causes a disease. This lead to postulating the "infectious dose", the minimal amount of bacteria that are necessary to trigger a disease. But microbiologists soon discovered that this is not so easy: apart from "factors of virulence" of the bacteria there are also susceptibility factors of the host. Indeed it was shown that co-exposure of bacteria and air pollutants increase the likelihood of an infectious disease: the damaged mucous membranes of the airways are more susceptible to the attack of germs. So what causes the disease? Most people would answer: "the germ, because we always find germs when there is an infection!" I could easily respond: "I checked it and I always found air pollution!"

I do not believe that finding germs establishes their causal role. What indeed does is therapeutic success: We are willing to accept those factors as "causal" which we can successfully influence. When I sit in a tram and a person besides me coughs or sneezes I automatically try to hold my breath until the germ bearing plume has settled. When I walk on the kerbside and a lorry passes by I try to do the same. Asthmatics could react to health warnings on high pollution days (Wen et al, 2009). Here the similarities between (chemical) air pollutants and infectious agents end: I have no antibiotics, no vaccination, no quarantine measures to offer to fight health effects of air pollution. It has been shown that good pharmacotherapy of asthma also mitigates exacerbations caused by air pollution (Song et al., 2009; Gilliland et al., 2009; Qian et al., 2009a; Trenga et al., 2006. But see also Quian et al., $2009 \mathrm{~b}$ ). But this is not a therapy against air pollution - it is simply good asthma therapy.

The individual doctor with her individual patient will not tackle air pollution, hence air pollution is outside her scope. But as a society we can really do something about air pollution while we are not very successful in fighting infectious agents: We have until now only conquered smallpox and polio might follow soon. In the meantime a whole bunch of new deadly viruses has been detected. Everywhere where people meet or come in contact with animals or even besides that, there is a risk of infection. Contrary to that our western civilisation was fairly successful in reducing air pollution. Indeed it was not until pollution levels were considerably reduced that epidemiologists were able to show that even low levels previously considered "safe" had in fact still an adverse effect on health.

3. Specificity: Causation is likely if a very specific population at a specific site and disease with no other likely explanation. The more specific an association between a factor and an effect is, the bigger the probability of a causal relationship.

4. Temporality: The effect has to occur after the cause (and if there is an expected delay between the cause and expected effect, then the effect must occur after that delay).

5. Biological gradient: Greater exposure should generally lead to greater incidence of the effect. However, in some cases, the mere presence of the factor can trigger the effect.

6. Plausibility: A plausible mechanism between cause and effect is helpful.

7. Coherence: Coherence between epidemiological and laboratory findings increases the likelihood of an effect.

8. Experimental evidence.

9. Analogy: The effect of similar factors may be considered. 
I therefore hold that as a society we should more seriously consider air pollution as cause of disease. But health-policy makers usually fail to make health-policy but rather engage in disease management. Their experts usually are learned doctors (if policy-makers do indeed ask experts) who know how to treat individual disease or have studied the economy of the healthcare system. "Environment" is usually out of the scope of both.

\section{The proof of the pudding}

"The proof of the pudding is in the eating", is an old proverb. The most suggestive proof of the causal effects of air pollution on health is the beneficial effect of air pollution reduction (Renzetti et al., 2009). Be it the unintended side effect of a year long strike at a steel plant (Ghio \& Delvin, 2001; Dye J et al., 2001; Pope et al., 1989) or of the short term improvements in air pollution due to a special transport scheme with restrictions of private cars during the Olympic Games in Atlanta (Friedman et al., 2001) or in Beijing (Wu et al., 2010) or during the 2002 summer Asian games in Busan (Lee et al., 2007). Even more impressive are the effects of specific measures with a lasting impact like the ban of coal sales in Dublin (Clancy et al., 2002) or in other Irish towns (Rich et al., 2009). The same holds true for the reduction of sulphur in fuels in Hong Kong (Hedley et al., 2002).

It is more difficult to show the benefit of gradually improving air quality that was seen over the last decades in many developed countries due to continuous technology improvements. A single measure that induces a significant improvement of air quality at once leads to a reduction in daily deaths. But fewer deaths in the short run will just make the age distribution of the population shift thus increasing that part of the population with the highest risk of dying. So in the long run daily death counts will not change: Everybody is bound to die exactly once. Therefore with gradually improving air quality no telling changes in daily mortality will be seen. We expect an increase in average life expectancy which indeed is the case in many countries. But two parallel trends like those of air quality and life expectancy are no proof of causal association. Indeed there are likely many causes of the increasing life expectancy and air quality is maybe not its most important cause.

It is reasonable to assume that death from air pollution will not affect all people equally. There are bound to be susceptibility factors like diabetes (Jacobs et al., 2010) but many are only partly understood by now and even include socio-economic factors (Barcelo et al., 2009). Improvements in air quality will therefore at the foremost increase the life expectancy of that group of people who are most susceptible towards air pollution. So we might expect that this group will increase in number relative to the whole population. In that case we would expect a steeper dose-response slope for air pollution and mortality with overall improving air quality. Indeed Shin et al. (2008) clearly showed this trend for Canada and nitrogen dioxide $\left(\mathrm{NO}_{2}\right)$ although they failed to interpret their finding as an indication of a beneficial effect of reduced $\mathrm{NO}_{2}$ levels.

\section{Relative risks}

Relative risks get increasingly criticised (Poole, 2010; Kaufman, 2010). But a high relative risk certainly is convincing. Consider a very rare disease, say, that occurs in one person only in every 100,000. Your doctor might not have seen this disease once and certainly not more often in her whole professional life. Then consider a group of people, say 500 workers in a 
special industrial plant, and of these five develop this disease: one in hundred, or a relative risk of 1000:1 (1:100/1:100,000)! That does tell us something, doesn't it? There must be an exposure in this plant that poses a very strong risk factor. This is really bad news for the 500 employees. But still for them it does not mean certain doom, only a one in hundred risk. Now consider a frequent disease like arteriosclerosis. One in three might develop it. And consider an agent we are all to a higher or lesser degree exposed to, like air pollution and the relative risk is negligible! Maybe RR is 1.01 (a one percent increase) or even less. No doctor will realise when she suddenly has one percent more patients with this diagnosis among her clients: She might have seen 10 of them each day. Now she sees one more every tenth day. Yet in each population of 1000 you would have approximately 3 additional cases, and we are not talking about small groups of 1000 people only but about all citizens of your country! So with this tiny relative risk we end up with many more affected people than with the huge risk and the 5 workers at the one industrial plant.

Frequent diseases usually are frequent because they do have multiple causes. So each cause will only contribute a small percentage to the disease. This makes recognising the cause a difficult task. But if the cause is widespread it still can mean a relevant number of additional diseases. This exactly is the case with air pollution.

\section{Duration of exposure}

We are always exposed to air and the air is never free of pollutants. Hence we are always exposed to air pollution. Nevertheless it might be different if we are exposed to an episode of very high pollution for a rather short time or if we are exposed to a lower concentration for a longer period (even so that the dose, which is the concentration multiplied by time, is the same). Analysing short or long term exposures calls for different study concepts.

For short exposures and acute effects two concepts are broadly used. The first is the panel study: you select a group of volunteers that, as they live on, are exposed to ever changing concentrations of air pollutants that you are somehow able to monitor. These volunteers undergo repeated medical check-ups like lung function testing or analysis of inflammatory or cardiovascular markers. By analysing your data you can investigate the effect of short term changes of air pollution on the selected health parameters. This approach allows you a deeper insight in the influences of biological mechanisms even before the outbreak of overt disease. But when you are interested in disease outcome you must keep in mind the small relative risks you might expect. Therefore you need large numbers of people and long observation periods for meaningful statistics. This is the realm of time series studies: These can rely mostly on public data. A person that has diabetes today will likely have diabetes tomorrow. She who smokes today will likely be a smoker tomorrow. He who lives in a poor crowded area today will usually do so tomorrow. All these individual factors therefore will not confound the effects of day-to-day variation in air pollution. Therefore you can use public data like daily mortality rate or hospital admissions as a health outcome. Also daily air pollution is available from urban monitoring networks. Only factors that also change on a temporal scale can confound the association and must be taken into account: season, weather, influenza epidemics, holidays and weekends. Weather and season are very likely confounders because they both affect health and air pollution levels, but they can easily be controlled for. On weekends consistently fewer deaths are reported. This might partly be a spurious finding when deaths on Sunday are only discovered and/or reported on Monday. 
But certainly there is also a true beneficial weekend effect. This is noteworthy because contrary to weather and season the weekend is not a natural phenomenon but a purely societal construct: It is the very way we organise our society that has a measurable effect on health! Maybe this information is already relevant for health policy: It does not matter so much if the final mechanism that makes workdays more dangerous is via societal stress, via noise, via air pollution (which is indeed lower on weekends), or via any other unknown route. It might be scientifically rewarding to disentangle the very contribution of air pollution. But for policy it is already important to know that "something" is wrong with the way we design our working days.

A typical outcome of time series studies on air pollution and mortality is "additional deaths per day per a certain change in air pollution concentration". For $10 \mu \mathrm{g} / \mathrm{m}^{3}$ of fine particles (PM2.5) this is in the magnitude of approximately $1 \%$. Cohort studies, that analyse the impact of long term air pollution exposure, produce a different outcome. To study long term exposure you cannot rely on day-to-day changes in air pollution but you must compare the health and fate of people that are continuously exposed to different levels of air pollution on average. A sensible choice would be to compare inhabitants of two (or more) cities with different average air pollution. The inhabitants of each city with certain characteristics (e.g. you could select people according to age group) are seen as a "cohort" (hence the name of the study concept), i.e. a group of people defined by common characteristics and an exposure level. Your interest lies in the fate of each cohort: do they differ in disease or mortality risk? So in mortality studies your outcome would not be (daily) counts of deaths but percentages of deaths per age-group and year, i.e. annual rates instead of daily counts. With the help of population tables you could easily translate differences of rates into differences of average life expectancy. This you cannot do with daily counts, because you do not know if a death prevented today leads to only a few additional days or to many more years of life.

Cohort studies are much more demanding than are time series analyses: When comparing different groups (cohorts) of people every characteristic that differs between the cohorts might confound the effects. So you must strive to collect as many data that are relevant to life expectancy as possible about all members of each cohort. These include age and sex, smoking behaviour, pre-existing disease status, job categories, educational and socioeconomic status, and many others. And still you cannot be sure that you have covered all possible confounding factors.

This is why cohort studies are rarer than time series. Nevertheless they find stronger effects: With time series a $10 \mu \mathrm{g} / \mathrm{m}^{3}$ change of PM2.5 led to an approximately $1 \%$ change in risk, with cohort studies this would typically be around $10 \%$. So it is encouraging to see that when you do time series studies and you look at increasingly longer exposure periods, e.g. look at the effects of same or previous day pollutants, then at effects of average pollution over the previous 2, 3, 4 days or 1 to 4 weeks you will usually find that the longer the averaging period the stronger the effect. This does lend additional support to the stronger findings of cohort studies.

The general concept states that one must be seriously ill to acutely die from an air pollution episode. But long exposure causes additional disease thus increasing the number of people at a high risk of death. Mechanisms of disease generation involve inflammatory processes (Jacobs et al., 2010; Flamant-Hulin et al., 2010; Thompson et al., 2010; Strak et al., 2010; Hildebrandt et al., 2009; Panasevich et al., 2009; Hoffmann et al., 2009), oxidative stress (Kang et al., 2010; Sawyer et al., 2010), mutagenicity of some air pollutants, and autonomic regulation of the cardiovascular system (Franchini \& Mannucci, 2009). 


\section{Source specific effects}

Linking pollutants' effects to certain sources has been done by source apportionment (Sarnat et al., 2008; Watson et al., 2008; Andersen et al., 2007; Ilacqua et al., 2007; Kim \& Hopke, 2007; Grahame \& Hidy, 2007; Chen et al., 2007; Brook et al., 2007; Zheng et al., 2007) through chemical tracers (Moreno et al., 2009; Patel et al., 2009, Delfino et al., 2009; Lin et al., 2010; Kleeman et al; 2009; Hwang et al.; 2008; John et al., 2007; Seagrave et al., 2006; Grahame \& Hidy, 2004) or GIS methods (Vienneau et al., 2009; Aguilera et al., 2009), making use of dispersion models (Jacquemin et al., 2009; Kostrzewa et al., 2009), land use regression techniques (Karr et al., 2009; Su et al., 2009), Bayesian structural equation models (Nikolovet al., 2007) or principal components analysis (McNabola et al., 2009; Sanchez et al., 2008).

Not all approaches are equally convincing. Morgan et al. (2010) set out to study the effect of bushfire smoke in Sydney, Australia. In this town fine particle concentrations (PM10) are usually low and only high on bushfire days. So they performed two different time series on daily mortality: one on high pollution days, and one on "normal" days. They found that the per $10 \mu \mathrm{g} / \mathrm{m}^{3}$ increase in daily deaths was stronger during "normal days" and concluded that PM10 from bushfire is less harmful than the usual urban PM mix. But the not so steep slope at higher concentrations could well be due to a saturation effect that leads to a nonlinear dose response curve and has nothing to do with the source of the pollutants.

Many different sources of air pollution have been investigated as causes of adverse health effects. These include, among others, municipal waste incinerators (Goria et al, 2009), residential heating (Junninen et al., 2009) and especially wood smoke (Karr et al., 2009; Naeher et al., 2007), local point sources (Karr et al., 2009) and even desert sand (Perez et al., 2008; Sandstrom \& Forsberg, 2008; Shinn et al., 2003). But more than any other sources road transport has been linked to adverse health effects (Adar and Kaufman, 2007; Fan et al., 2009; Brunekreef et al., 2009; Rosenlund et al., 2009; Migliore et al., 2009; Hart et al., 2009; Delfino et al., 2009; Aguilera et al., 2009; Perez et al., 2009a; Perez et al., 2009b; Kramer et al., 2009; Kunzli et al., 2009; Tonne et al., 2009; Ranft et al., 2009; Pedersen et al., 2009; Ryan et al., 2009; Eisner et al., 2009; Gent et al., 2009; Ho et al., 2010). Only few studies (e.g. PujadesRodriguez et al., 2009) could not confirm this association. In these and many more studies exposure to road transport has been estimated by considering current home or school address or a history of past home addresses. For these addresses exposure was assessed using proxies like distance to next busy road, number of vehicles per day on the road next to the home, or a combination of both, or more advanced models also taking wind direction etc. into account. Various health endpoints were investigated. Therefore in spite of the impressive list of studies even for road traffic derived air pollution some more research is needed before firm conclusions as to the underlying sources and effects can be drawn and reliable dose-effect relations can be described. Regarding the sources it still is not clear which exhaust-pipe emissions are the main culprits nor to what extent other transportrelated emissions including noise and mechanically generated particles like tire or break wear or re-suspended road dust contribute to the various effects. This makes it difficult to estimate the relative impact of any specific technical measure like a filter or an innovative propulsion technique. What can be recommended clearly and without hesitation is to generally reduce road traffic in inhabited (urban) areas and/or not to place sensitive exposure groups (like children through kindergartens or schools) near busy roads.

The knowledge base is much less advanced for other sources of air pollution where there are only few studies for each specific source and exposure situation often varies fundamentally 
according to specific local circumstances like meteorological conditions or the exact technical specification of the very source: not one power plant or one waste incinerator is exactly the same as the others.

\section{The phrasing of the message}

Telling policy makers and the public what to do is not easy for many reasons. First of all scientists do not want to tell others "what to do" but their first goal is to get additional funds to carry on their interesting research. Secondly, policy makers, media people, and the general public do not want to hear what scientists have to tell but what fits their current interests. Third, as we have seen above, there is still not a clear-cut message regarding specific sources and measures: Evidence based measures are bound to be based on a costbenefit analysis. But as long as the benefits cannot be quantified for lack of source and measure specific dose-response functions we are still a far way off the mark.

Fourth, when it comes to cost-benefit statements, these are outside the narrow scope of environmental health science. Comparing benefits and costs intrinsically necessitates the monetary valuation of health benefits. But deciding on the value of reduced health risks is the task of society, not of scientists. Scientists are burdened with the task of explaining the magnitude of the risks (even including the uncertainties linked to this magnitude estimate) in an understandable, meaningful and correct way.

The European Public Health Project "Aphekom" (http://www.aphekom.org) set out to (among other things) clarify the public's information needs: "What would be the best metric to explain the health impact of air pollution?" was just one of the questions a panel of air pollution scientists were asked at the Aphekom symposium during the ISEE conference in Dublin (Medina et al., 2009). Death is the most emotional outcome of air pollution. So not surprisingly much of the discussion centred on the question how changes in mortality risk were best described. There is a long ongoing debate whether "number of deaths" or "changes on life expectancy" or even "disability adjusted life expectancy" would be the better metric (Brunekreef and Hoek, 2000).

At that workshop Bert Brunekreef again explained his position: "It is methodologically more correct to express the effects in the terms of disability adjusted life years and life expectancy rather than numbers of deaths or numbers of cases. But still we tend to think that the media and the public want to hear the numbers rather than the years of life lost.

But when I teach about these issues I use to start my presentation with a very simple question to the audience: What matters more to you, what you're going to die from eventually or how many years you're going to live in reasonably good health? And no audience so far said that they want to know what they are going to die from, they are much more interested in how long they're going to live in a reasonably good health."

Christophe Declercq mostly agreed with that position: "At the population level, the number of attributable cases by year is only an approximation. If the level of particulate matter decreases, agespecific mortality rates of the exposed population will decrease. In the long term, the age structure will change as people will live longer. This will cause the mortality rates and the number of deaths by year to increase again. Therefore, from a theoretical point of view, the gain in life expectancy is a better metric than the number of attributable cases. This is true in the long term, fifty years or so, but for the next years to come, attributable cases can still be a useful approximation if it is simpler to communicate." 
Joel Schwartz strongly disagreed with the position that "years of life lost" is better than "number of deaths": "First of all, individual people would like to know how long they're going to live but we can't tell them that at all. We can tell them that an intervention that lowers air pollution changes average life expectancy but might not change theirs or might change it a lot more than average, so that's not anything that we can tell them. What can we tell them, what is the product that we're offering to sell them if society diverts some resources into pollution prevention? We can tell them that their risk goes down and there is a large and extensive literature on how people value reductions to risk. And that literature is uniformly reporting that years of life lost is not the metric that people value! The evidence of that is as strong as the evidence that cigarettes smoking causes lung cancer:

If years of life lost were the metric which people value reductions in risk then one would expect a roughly linear decline in the bid with the age of the participants because 80 year-olds are not going to increase their life expectancy by nearly as much as 40 year-olds by this constant 1 in 10,000 reduction in risk each year. And so that's an empirically testable hypothesis and there was absolutely no association between what people were willing to pay and their age, in none of several studies done in the US, in Canada, in the UK."

Now I neither know what I would pay to get a certain percentage risk reduction nor what I would be willing to do for an additional year of life. I can understand "ten additional deaths" in a month or in a year in a certain population. I do not understand what a reduction in life expectancy by a few weeks or months means: Even if it were my personal life expectancy: I'd not so much want to know how much longer or shorter I live, but what will be the exact duration. Reducing my life expectancy by 3 weeks could mean I have to die tomorrow or in 40 years. So it is no meaningful information for me! Likewise it is not surprising that media and the public love "the numbers". In the same workshop Marco Martuzzi gave an example that even the "wrong" numbers are nearly as good: "We estimated the deaths attributed to air pollution for the main Italian cities and came up with unusually large numbers which activated some debate. This was quite influential at the national level and mobilized a number of people.

However some time later we were also invited by one of the cities. They had a heated debate regarding stricter measures for air pollution control and there was a tense situation with citizens and NGOs on one side and the local authorities on the other and we were asked to go there and present and discuss our study results. We arrived there and the situation was indeed quite tense and on the day of the event there had been headlines on the local papers saying: 50 deaths per year attributable to air pollution! In the heated discussion some said this is totally intolerable while others argued that compared to smoking this would be a very small and absolutely acceptable impact. After a while we were able to speak and to point out that they had got it wrong: it was 500, not 50 deaths per year! There was a moment of void but in the end nothing changed! The debate went on exactly the same!"

So if the numbers really seem to be meaningless it is no wonder that Christophe Declercq argued for new aspects in communication: "I see the problem in the translation from the population level to the individual level. When you talk to the press or to the general public, and mention a number of attributable deaths, they will ask who are the victims. But we cannot answer to this question yet. But this question is not a bad question though. We know that there are inequalities in exposure to air pollution, which is higher for example in people living in proximity to the traffic, Some studies also suggest inequalities in the health effects of air pollution, and that this differential vulnerability is linked to the social status of the exposed population. So air pollution exposure and effects contribute to social inequalities in health. We need more research in this area, but what we already know should urge us to go beyond a summary indicator of health impact of air pollution, be it 
number of attributable cases or life expectancy. If we want to assess benefits of air pollution public policies, we should also check that the more exposed and the more vulnerable part of the population gets larger benefits in terms of air quality and health."

Also Nino Künzli, who was one of the first to embark on the health impact assessment of air pollution (Künzli et al., 2000), warned against a too narrow look at mortality effects. But first he looked back to his seminal paper: "The derivation and the communication of risks based on epidemiological research has a long tradition and if we take the example of smoking it has not even been much debated how we do that and how we communicate that. Such billboards are shown all over the world to communicate to people how many deaths are attributable to smoking. These numbers are simply estimates of attributable risks taking the association between smoking and death and the prevalence of smoking into account.

Some 10 years ago we applied these methods to answer a hot question asked by the ministers of health and environment of France, Austria and Switzerland: what is the health impact and what are the costs that can be attributed to ambient air pollution?

While I do not consider this my most important paper it became indeed the most cited one of all I wrote so far. And why that? Because of the numbers of attributable deaths, we estimated 40,000 attributable deaths per year due to air pollution. These numbers more than any other result in this same paper kept the world media quite busy and interested for years."

After also discussing "years of life lost" (the more accurate metric) and "number of deaths" (the more intuitive metric) he went on with - what he called - a provocative statement: "No matter what we use - either attributable deaths or years of life lost - we mislead and we distract from the relevant issues. Why that?

Let me explain this with the lifetime model of the development of chronic states, of chronic diseases which of course increase with age. Mortality - be it expressed as numbers or years - comes only at the very end after the development of all these chronic pathologies. The state of health however is what matters. It is the timing of this lifetime period that matters. It is health that matters and it is health or the reduced health that ultimately determines our life time and our life expectancy.

We are exposed over life time and this exposure entertains the development of chronic pathologies leading to lots of morbidities during life time and ultimately to premature death. We should invest far more in communicating that part of the air pollution related adverse effects.

However, to focus the risk assessment on morbidity requires an expansion of our methodologies and an in-depth discussion with economists as well who continue to attach far higher monetary value to death. Also we all know that part of this money is virtual and we know that the morbidity is far less and less completely monetized and monetization is even based on different methodologies. So we should emphasize what happens during life prior to death but how should we do this in the risk assessment framework?"

Nino Künzli went on to discuss the combined impact of long-term and acute exposure towards air pollution: chronic exposure is known to enhance or even cause arteriosclerosis (Hoffmann et al., 2007; Künzli et al., 2005; Sun et al., 2005). And if arteriosclerosis of the coronary arteries is present acute exposures can trigger myocardial infarction (Peters et al., 2001). Similar phenomena are observed with respiratory disease: Chronic and especially early life exposure increases the prevalence of asthma (McConnell et al., 2006). And asthmatics react to acute air pollution episodes with more and more severe asthma attacks. It is still a challenge to present this combined effect of chronic and acute exposures in health impact assessments (Künzli et al., 2008). This in fact is the job of Nino Künzli's workpackage in the project Aphekom. 
The symposium in Dublin clearly showed the interest of the ongoing work on this issue in the Aphekom project which focuses on the need to improve the communication efforts and to fine-tune the relevant messages for the needs of the various stakeholders.

\section{Conclusion}

Adverse health effects of air pollution are well established. Experimental toxicological studies have shed light on relevant mechanisms and epidemiological data inform on the population relevance and the magnitude of the effects under realistic exposure scenarios. More recent research set out to define susceptible population subgroups. This will allow answering the question "who are the victims?" This question is of high policy relevance, but even more important is the question who the culprits are. Regarding sources there is ample evidence that proximity to road traffic poses serious health risks but other sources of air pollution including natural and industrial sources are likely equally dangerous as the average air pollution mixture on a mass concentration basis of currently used pollutants indicators $\left(\mathrm{NO}_{2}, \mathrm{PM} 2.5\right)$.

Research is ongoing to better define the impact of specific pollution sources and to better understand the effects of the whole pollution mixture as compared to a "pollutant-bypollutant" approach (Dominici et al., 2010). This is already reflected by a shift also in the policy frameworks (Greenbaum \& Shaikh, 2010). Nevertheless there is still a far way to go. But gaps in current knowledge should not serve as an excuse for non-action: Where measures to improve air quality are feasible public health advantages are so striking that any cost-benefit analysis even in the light of uncertainty clearly proves that action is superior to non-action. So acting is not a question of uncertainty of benefits. In-action is caused by the difficulties in understanding health impacts and assessing these in relation to other interests that might not be as pressing, but easier to understand. Also the pressure of strong interest groups is often more successful than health concerns.

Knowledge about culprits and victims empowers science to inform policy. But communicating small relative risks that render individual preventive measures less effective but still are relevant for the whole population is still a demanding task. The public wants and deserves clear and easily understandable answers. The reality might just be a trifle too complicated for that.

\section{References}

Adar, S.D. \& Kaufman, J.D. (2007). Cardiovascular disease and air pollutants: evaluating and improving epidemiological data implicating traffic exposure, Inhalation Toxicology, 19, Suppl 1, 135-149, ISSN: 0895-8378

Aguilera, I. et al. (2009). Association between GIS-based exposure to urban air pollution during pregnancy and birth weight in the INMA Sabadell Cohort, Environmental Health Perspectives, 117, 8, 1322-1327, ISSN: 0091-6765

Andersen, Z.J. et al. (2007). Ambient particle source apportionment and daily hospital admissions among children and elderly in Copenhagen, J Expo Sci Environ Epidemiol, 17, 7, 625-636, ISSN: 1559-0631 
Barcelo, M.A. et al. (2009). Spatial variability in mortality inequalities, socioeconomic deprivation, and air pollution in small areas of the Barcelona Metropolitan Region, Spain, Science of the Total Environment, 407, 21, 5501-5523, ISSN: 0048-9697

Brook, J.R. et al. (2007). Assessing sources of PM2.5 in cities influenced by regional transport, Journal of Toxicology \& Environmental Health Part A, 70, 3-4, 191-199, ISSN: 1528-7394

Brunekreef, B. \& Hoek, G. (2000), Invited Commentary - Beyond the Body Count: Air Pollution and Death, American Journal of Epidemiology, 151, 5, 449-451, ISSN: 00029262

Brunekreef, B. et al. (2007). The Brave New World of Lives Sacrificed and Saved, Deaths Attributed and Avoided, Epidemiology, 18, 6, 785-788, ISSN: 1044-3983

Brunekreef, B. et al. (2009). Effects of long-term exposure to traffic-related air pollution on respiratory and cardiovascular mortality in the Netherlands: the NLCS-AIR study, Research Report - Health Effects Institute, 139, 5-71, ISSN: 1041-5505

Chen, L.W. et al. (2007). Quantifying PM2.5 source contributions for the San Joaquin Valley with multivariate receptor models, Environmental Science \& Technology 41, 8, 28182826, ISSN: 0013-936X

Clancy, L. et al. (2002). Effect of air-pollution control on death rates in Dublin, Ireland: an intervention study, Lancet, 36, 1210-1214, ISSN: 0140-6736

Delfino, R.J. et al. (2009). Air pollution exposures and circulating biomarkers of effect in a susceptible population: clues to potential causal component mixtures and mechanisms, Environmental Health Perspectives 117, 8, 1232-1238, ISSN: 00916765

Dominici, F. et al. (2010). Protecting human health from air pollution: shifting from a singlepollutant to a multipollutant approach, Epidemiology, 21, 2, 187-194, ISSN: 1044-3983

Dye, J.A. et al. (2001). Acute Pulmonary Toxicity of Particulate Matter Filter Extracts in Rats: Coherence with Epidemiologic Studies in Utah Valley Residents, Environmental Health Perspectives, 109, Suppl 3, 395-403, ISSN: 0091-6765

Eisner, A.D. et al. (2009). Establishing a link between vehicular PM sources and PM measurements in urban street canyons, Journal of Environmental Monitoring, 11, 12, 2146-2152, ISSN: 1464-0325

Evans, A.S. (1976). Causation and disease: the Henle-Koch postulates revisited, Yale J Biol Med, 49, 2, 175-195, ISSN: 0044-0086

Falkow, S. (1988). Molecular Koch's postulates applied to microbial pathogenicity, Rev Infect Dis, 10, Suppl 2, S274-S276, ISSN: 0162-0886

Fan, Z.T. et al. (2009). Acute exposure to elevated PM2.5 generated by traffic and cardiopulmonary health effects in healthy older adults, Journal of Exposure Science $\mathcal{E}$ Environmental Epidemiology, 19, 5, 525-533, ISSN: 1559-0631

Flamant-Hulin, M. et al. (2010). Air pollution and increased levels of fractional exhaled nitric oxide in children with no history of airway damage, J Toxicol Environ Health A, 73, 4, 272-283, ISSN: 1528-7394

Franchini, M. \& Mannucci, P.M. (2009). Particulate air pollution and cardiovascular risk: short-term and long-term effects, Semin Thromb Hemost, 35, 7, 665-670, ISSN: 00946176

Friedman, M.S. et al. (2001). Impact of changes in transportation and commuting behaviors during the 1996 Summer Olympic Games in Atlanta on air quality and childhood asthma, Journal of the American Medical Association, 285, 7, 897-905, ISSN: 00987484 
Gent, J.F. et al. (2009). Symptoms and medication use in children with asthma and trafficrelated sources of fine particle pollution, Environmental Health Perspectives, 117, 7, 1168-1174, ISSN: 00916765

Ghio, A.J. \& Delvin, R.B. (2001). Inflammatory Lung Injury after Bronchial Instillation of Air Pollution Particles, Am J Respir Crit Care Med, 164, 704-708, ISSN: 1073-449X

Gilliland, F.D. et al. (2009). Outdoor air pollution, genetic susceptibility, and asthma management: opportunities for intervention to reduce the burden of asthma, Pediatrics, 123, Suppl 3, S168-S173, ISSN: 0031-4005

Goria, S. et al. (2009). Risk of cancer in the vicinity of municipal solid waste incinerators: importance of using a flexible modelling strategy, International Journal of Health Geographics, 8, 31, ISSN: 1476-072X

Grahame, T. \& Hidy, G. (2004). Using factor analysis to attribute health impacts to particulate pollution sources, Inhalation Toxicology, 16, Suppl 1, 143-152, ISSN: 08958378

Grahame, T. \& Hidy, G.M. (2007). Pinnacles and pitfalls for source apportionment of potential health effects from airborne particle exposure, Inhalation Toxicology, 19, 9, 727-744, ISSN: 0895-8378

Greenbaum, D. \& Shaikh, R. (2010). Commentary: First steps toward multipollutant science for air quality decisions, Epidemiology, 21, 2, 187-194, ISSN: 1044-3983

Hart, J.E. et al. (2009). Exposure to traffic pollution and increased risk of rheumatoid arthritis, Environmental Health Perspectives, 117, 7, 1065-1069, ISSN: 00916765

HEI Health Effects Institute (2000). Special report: Reanalysis of the Harvard Six Cities Study and the American Cancer Society Study of Particulate Air Pollution and Mortality: http://pubs.healtheffects.org/view.php?id=6

HEI Health Effects Institute (2003). Special report: Revised Analyses of Time-Series Studies of Air Pollution and Health: http:// pubs.healtheffects.org/view.php?id=4

Health Effects Institute (2007). Special report 16: Mobile-Source Air Toxics: A Critical Review of the Literature on Exposure and Health Effects: http:/ / pubs.healtheffects.org/view.php?id=282

Health Effects Institute (2010). Special report 17: Traffic-Related Air Pollution: A Critical Review of the Literature on Emissions, Exposure, and Health Effects: http:/ / pubs.healtheffects.org/view.php?id=334

Hedley, A.J. et al. (2002). Cardiorespiratory and all-cause mortality after restrictions on sulphur content of fuel in Hong Kong: an intervention study, Lancet 360: 1646-1652, ISSN: 0140-6736

Hildebrandt, K. et al. (2009). Short-term effects of air pollution: a panel study of blood markers in patients with chronic pulmonary disease, Particle and Fibre Toxicology, 26, 6-25, ISSN: $1743-8977$

Hill, A.B. (1965). The environment and disease: association or causation? Proceedings of the Royal Society of Medicine, 58, 295-300, ISSN: 0035-9157

Ho, C.K. et al. (2010). Traffic air pollution and risk of death from bladder cancer in Taiwan using petrol station density as a pollutant indicator, Journal of Toxicology $\mathcal{E}$ Environmental Health Part A, 73, 1, 23-32, ISSN: 1528-7394

Hoffmann, B. et al. (2007). Residential exposure to traffic is associated with coronary arteriosclerosis, Circulation, 116, 489-496, ISSN: 0009-7322 
Hoffmann, B. et al. (2009). Chronic residential exposure to particulate matter air pollution and systemic inflammatory markers, Environmental Health Perspectives, 117, 8, 13021308, ISSN: 0091-6765

Hwang, I. et al. (2008). Source apportionment and spatial distributions of coarse particles during the Regional Air Pollution Study, Environmental Science E Technology, 42, 10, 3524-3530, ISSN: 0013-936X

Ilacqua, V. et al. (2007). Source apportionment of population representative samples of $\operatorname{PM}(2.5)$ in three European cities using structural equation modelling, Science of the Total Environment, 384, 1-3, 77-92, ISSN: 0048-9697

Jacobs, L. et al. (2010). Air pollution related prothrombotic changes in persons with diabetes, Environmental Health Perspectives, 118, 2, 191-196, ISSN: 0091-6765

Jacquemin, B. et al. (2009). Association between modelled traffic-related air pollution and asthma score in the ECRHS, European Respiratory Journal, 34, 4, 834-842, ISSN: 09031936

John, K. et al. (2007). Analysis of trace elements and ions in ambient fine particulate matter at three elementary schools in Ohio, Journal of the Air $\mathcal{E}$ Waste Management Association, 57, 4, 394-406, ISSN: 1047-3289

Junninen, H. et al. (2009). Quantifying the impact of residential heating on the urban air quality in a typical European coal combustion region, Environmental Science $\mathcal{E}$ Technology, 43, 20, 7964-7970, ISSN: 0013-936X

Kang, X. et al. (2010). Adjuvant effects of ambient particulate matter monitored by proteomics of bronchoalveolar lavage fluid, Proteomics, 10, 3, 520-531, ISSN: 16159853

Karr, C.J. et al.(2009). Influence of ambient air pollutant sources on clinical encounters for infant bronchiolitis, American Journal of Respiratory \& Critical Care Medicine, 180, 10, 995-1001, ISSN: 1073-449X

Kaufman, J.S. (2010). Toward a More Disproportionate Epidemiology, Epidemiology, 21, 1, 12, ISSN: 1044-3983

Kim, E. \& Hopke, P.K. (2007). Source identifications of airborne fine particles using positive matrix factorization and U.S. Environmental Protection Agency positive matrix factorization, Journal of the Air \& Waste Management Association, 57, 7, 811-819, ISSN: 1047-3289

Kleeman, M.J. et al. (2009). Source apportionment of fine (PM1.8) and ultrafine (PM0.1) airborne particulate matter during a severe winter pollution episode, Environmental Science \& Technology, 43, 2, 272-279, ISSN: 0013-936X

Koch, R. (1884). Die Aetiologie der Tuberkulose, Mitt Kaiser Gesundh, 1884, 1-88

Kostrzewa, A. et al. (2009). Validity of a traffic air pollutant dispersion model to assess exposure to fine particles, Environmental Research, 109, 6, 651-656, ISSN: 0013-9351

Krämer, U. et al. (2009). Eczema, respiratory allergies, and traffic-related air pollution in birth cohorts from small-town areas, Journal of Dermatological Science, 56, 2, 99-105, ISSN: 0923-1811

Kundi, M. (2006). Causality and the Interpretation of Epidemiologic Evidence, Environmental Health Perspectives, 114, 969-974, ISSN: 0091-6765

Künzli, N. et al. (2000). Public-health impact of outdoor and traffic-related air pollution: a European assessment, Lancet, 356, 9232, 795-801, ISSN: 0140-6736 
Künzli, N. et al. (2005). Ambient air pollution and atherosclerosis in Los Angeles, Environmental Health Perspectives, 113, 201-206, ISSN: 0091-6765

Künzli, N. et al. (2008). An Attributable Risk Model for Exposures Assumed to Cause Both Chronic Disease and its Exacerbations, Epidemiology, 19, 2, 179-185, ISSN: 1044-3983

Künzli, N. et al. (2009). Traffic-related air pollution correlates with adult-onset asthma among never-smokers, Thorax, 64, 8, 664-670, ISSN: 0040-6376

Lee, J.T. et al. (2007). Benefits of mitigated ambient air quality due to transportation control on childhood asthma hospitalization during the 2002 summer Asian games in Busan, Korea, Journal of the Air \& Waste Management Association, 57, 8, 968-973, , ISSN: 1047-3289

Lin, L. et al. (2010). Review of recent advances in detection of organic markers in fine particulate matter and their use for source apportionment, Journal of the Air $\mathcal{E}$ Waste Management Association, 60, 1, 3-25, ISSN: 1047-3289

McConnell, R. et al. (2006). Traffic, susceptibility, and childhood asthma, Environmental Health Perspectives, 114, 766-772, ISSN: 0091-6765

McNabola, A. et al. (2009). A principal components analysis of the factors effecting personal exposure to air pollution in urban commuters in Dublin, Ireland, Journal of Environmental Science \& Health Part A, 44, 12, 1219-1226, ISSN: 1093-4529

Medina, S. et al. (2009). Communicating Air Pollution and Health Research to Stakeholders. Aphekom Symposium for the 21st ISEE Conference in Dublin, Ireland. 2009/08/26. http:/ / www.aphekom.org/c/document_library/get_file?uuid=9dbc8f44-64474a08-b81a-56b351a1f7a3\&groupId=10347

Migliore, E. et al. (2009). Respiratory symptoms in children living near busy roads and their relationship to vehicular traffic: results of an Italian multicenter study (SIDRIA 2), Environmental Health: A Global Access Science Source, 8, 27, ISSN: 1476-069X

Moreno, T. et al. (2009). Identification of chemical tracers in the characterisation and source apportionment of inhalable inorganic airborne particles: an overview, Biomarkers, 14, Suppl 1, 17-22, ISSN 1354-750X

Morgan, G. et al. (2010). Effects of Bushfire Smoke on Daily Mortality and Hospital Admissions in Sydney, Australia, Epidemiology, 21,1, 47-55, ISSN: 1044-3983

Naeher, L.P. et al. (2007). Woodsmoke Health Effects: A Review, Inhalation Toxicology, 19, 67-106, ISSN: 0895-8378

Nikolov, M.C. et al. (2007). An informative Bayesian structural equation model to assess source-specific health effects of air pollution, Biostatistics, 8, 3, 609-624, ISSN 14654644

Panasevich, S. (2009). Associations of long- and short-term air pollution exposure with markers of inflammation and coagulation in a population sample, Occup Environ Med, 66, 11, 747-753, ISSN: 1470-7926

Patel, M.M. et al. (2009). Ambient metals, elemental carbon, and wheeze and cough in New York City children through 24 months of age, American Journal of Respiratory $\mathcal{E}$ Critical Care Medicine, 180, 11, 1107-1113, ISSN: 1073-449X

Pedersen, M. et al. (2009). Increased micronuclei and bulky DNA adducts in cord blood after maternal exposures to traffic-related air pollution, Environmental Research, 109, 8, 1012-1020, ISSN: 0013-9351 
Perez, L. et al. (2009a). Global goods movement and the local burden of childhood asthma in southern California, American Journal of Public Health, 99, Suppl 3, S622-628, ISSN: 0090-0036

Perez, L. et al. (2009b). Size fractionate particulate matter, vehicle traffic, and case-specific daily mortality in Barcelona, Spain, Environmental Science \& Technology, 43, 13, 4707-4714, ISSN: 0013-936X

Perez, L. et al. (2008). Coarse particles from Saharan dust and daily mortality, Epidemiology, 19, 6, 800-807 ISSN: 1044-3983

Peters, A. et al. (2001). Increased particulate air pollution and the triggering of myocardial infarction, Circulation, 103, 2810-2815, ISSN: 0009-7322

Phillips, C.V. \& Karen J.G. (2004). The missed lessons of Sir Austin Bradford Hill, Epidemiologic Perspectives and Innovations, 1, 3, 3, ISSN: 1742-5573

Poole, C. (2010). On the Origin of Risk Relativism, Epidemiology, 21, 1, 3-9, ISSN: 1044-3983

Pope, C.A. III. (1989). Respiratory disease associated with community air pollution and a steel mill, Utah Valley, Am J Public Health, 79, 623-628, ISSN: 1541-0048

Pujades-Rodriguez, M. (2009). Effect of living close to a main road on asthma, allergy, lung function and chronic obstructive pulmonary disease, Occupational $\mathcal{E}$ Environmental Medicine, 66, 10, 679-684, ISSN: 1351-0711

Qian, Z. et al. (2009a). Associations between air pollution and peak expiratory flow among patients with persistent asthma, J Toxicol Environ Health A, 72, 1, 39-46, ISSN: 15287394

Qian, Z. et al. (2009b): Interaction of ambient air pollution with asthma medication on exhaled nitric oxide among asthmatics, Arch Environ Occup Health, 64, 3, 168-176, ISSN: 1933-8244

Ranft, U. et al. (2009). Long-term exposure to traffic-related particulate matter impairs cognitive function in the elderly, Environmental Research, 109, 8, 1004-1011, ISSN: 0013-9351

Renzetti, G. et al. (2009). Less air pollution leads to rapid reduction of airway inflammation and improved airway function in asthmatic children, Pediatrics, 123, 3, 1051-1058, ISSN: 0031-4005

Rich, D. et al. (2009). Effect of Air Pollution Control on Mortality in County Cork, Ireland, Epidemiology, 20, 6, S69, ISSN: 1044-3983

Rifkin, E. \& Bouwer, E. (2008). The Illusion of Certainty, Springer, ISBN-13: 978-0-387-75165-8, New York

Rosenlund, M. et al. (2009). Traffic-related air pollution in relation to respiratory symptoms, allergic sensitisation and lung function in schoolchildren, Thorax, 64, 7, 573-580, ISSN: 0040-6376

Ryan, P.H. et al. (2009). Exposure to traffic-related particles and endotoxin during infancy is associated with wheezing at age 3 years, American Journal of Respiratory $\mathcal{E}$ Critical Care Medicine, 180, 11, 1068-1075, ISSN: 1073-449X

Sandstrom, T. \& Forsberg B. (2008). Desert dust: an unrecognized source of dangerous air pollution? Epidemiology, 19, 6, 808-809, ISSN: 1044-3983

Sarnat, J.A. et al. (2008). Fine particle sources and cardiorespiratory morbidity: an application of chemical mass balance and factor analytical source-apportionment methods, Environmental Health Perspectives, 116, 4, 459-466, ISSN: 00916765 
Sanchez, M. et al. (2008). Source characterization of volatile organic compounds affecting the air quality in a coastal urban area of South Texas, International Journal of Environmental Research \& Public Health, 5, 3, 130-138, ISSN: 1660-4601

Sawyer, K. et al. (2010). The effects of ambient particulate matter on human alveolar macrophage oxidative and inflammatory responses, J Toxicol Environ Health A, 73, 1, 41-57, ISSN: 1528-7394

Seagrave, J. et al. (2006). Lung toxicity of ambient particulate matter from southeastern U.S. sites with different contributing sources: relationships between composition and effects, Environmental Health Perspectives, 114, 9, 1387-1393, ISSN: 00916765

Shin, H.S. et al. (2008). A Temporal, Multicity Model to Estimate the Effects of Short-Term Exposure to Ambient Air Pollution on Health, Environmental Health Perspectives, 116, 1147-1153, ISSN: 00916765

Shinn, E.A. et al. (2003). Atmospheric transport of mold spores in clouds of desert dust, Archives of Environmental Health, 58, 8, 498-504, ISSN: 0003-9896

Song, D.J. et al. (2009). Environmental tobacco smoke exposure does not prevent corticosteroids reducing inflammation, remodeling, and airway hyperreactivity in mice exposed to allergen, Am J Physiol Lung Cell Mol Physiol, 297, 2, L380-L387, ISSN: 1040-0605

Strak, M. et al. (2010). Respiratory health effects of ultrafine and fine particle exposure in cyclists, Occup Environ Med, 67, 2, 118-124, ISSN: 1076-2752

$\mathrm{Su}$, J.G. (2009). Predicting traffic-related air pollution in Los Angeles using a distance decay regression selection strategy, Environmental Research, 109, 6, 657-670, ISSN: 00139351

Sun, Q. et al. (2005). Long-term air pollution exposure and acceleration of atherosclerosis and vascular inflammation in an animal model, Journal of the American Medical Association, 294, 3003-3010, ISSN: 0098-7484

Thompson, A.M. et al. (2010). Baseline Repeated Measures from Controlled Human Exposure Studies: Associations between Ambient Air Pollution Exposure and the Systemic Inflammatory Biomarkers IL-6 and Fibrinogen, Environmental Health Perspectives, 118, 1, 120-124, ISSN: 0091-6765

Tonne, C. et al. (2009). Traffic particles and occurrence of acute myocardial infarction: a casecontrol analysis, Occupational E Environmental Medicine, 66, 12, 797-804, ISSN: 13510711

Trenga, C.A. et al. (2006). Effect of particulate air pollution on lung function in adult and pediatric subjects in a Seattle panel study, Chest, 129, 6, 1614-1622, ISSN: 0012-3692

Vienneau, D. et al. (2009). A GIS-based method for modelling air pollution exposures across Europe, Science of the Total Environment, 408, 2, 255-266, ISSN: 0048-9697

Walker, L et al. (2006). Koch's postulates and infectious proteins, Acta Neuropathol, 112, 1, 14, ISSN: 0001-6322

Watson, J.G. et al. (2008). Source apportionment: findings from the U.S. Supersites Program., Journal of the Air \& Waste Management Association, 58, 2, 265-288, ISSN: 1047-3289

Wen, X.J. et al. (2009). Association between media alerts of air quality index and change of outdoor activity among adult asthma in six states, BRFSS, 2005, J Community Health, 34, 1, 40-46, ISSN: 0094-5145 
WHO World Health Organization, Regional Office for Europe (2000). Air quality guidelines for Europe, Second edition. WHO Regional Publications, European Series, No. 91: http:/ / www.euro.who.int/document/e71922.pdf

World Health Organization, Regional Office for Europe (2005). WHO air quality guidelines. Global update 2005. Report on a Working Group meeting, Bonn, Germany, 18-20 October 2005: http:/ / www.euro.who.int/Document/E87950.pdf

WHO World Health Organization (2006). WHO Air quality guidelines for particulate matter, ozone, nitrogen dioxide and sulfur dioxide. Global update 2005. Geneva: http://whqlibdoc.who.int/hq/2006/WHO_SDE_PHE_OEH_06.02_eng.pdf

WHO World Health Organization, Regional Office for Europe (2007). Health relevance of particulate matter from various sources. Report on a WHO Workshop. Bonn, Germany, 26-27 March 2007: http:/ /www.euro.who.int/Document/E90672.pdf

Wu, S. et al. (2010). Association of Heart Rate Variability in Taxi Drivers with Marked Changes in Particulate Air Pollution in Beijing in 2008, Environmental Health Perspectives, 118, 1, 87-91, ISSN: 0091-6765

Zheng, M. et al. (2007). Source apportionment of daily fine particulate matter at Jefferson Street, Atlanta, GA, during summer and winter, Journal of the Air $\mathcal{E}$ Waste Management Association, 57, 2, 228-242, ISSN: 1047-3289 


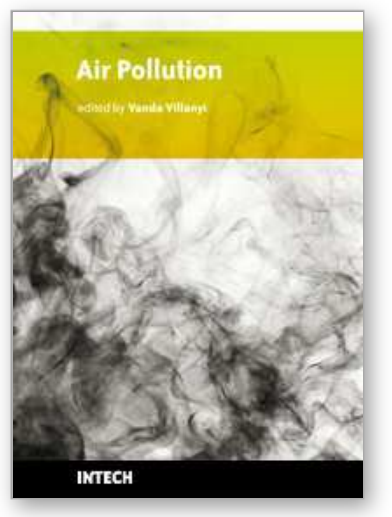

\author{
Air Pollution \\ Edited by Vanda Villanyi
}

ISBN 978-953-307-143-5

Hard cover, 370 pages

Publisher Sciyo

Published online 17, August, 2010

Published in print edition August, 2010

Although the climate of the Earth is continually changing from the very beginning, anthropogenic effects, the pollution of the air by combustion and industrial activities make it change so quickly that the adaptation is very difficult for all living organisms. Researcher's role is to make this adaptation easier, to prepare humankind to the new circumstances and challenges, to trace and predict the effects and, if possible, even decrease the harmfulness of these changes. In this book we provide an interdisciplinary collection of new studies and findings on the score of air pollution.

\title{
How to reference
}

In order to correctly reference this scholarly work, feel free to copy and paste the following:

Hanns Moshammer (2010). Communicating Health Impact of Air Pollution, Air Pollution, Vanda Villanyi (Ed.), ISBN: 978-953-307-143-5, InTech, Available from: http://www.intechopen.com/books/airpollution/communicating-health-impact-of-air-pollution

\section{INTECH}

open science | open minds

\section{InTech Europe}

University Campus STeP Ri

Slavka Krautzeka 83/A

51000 Rijeka, Croatia

Phone: +385 (51) 770447

Fax: +385 (51) 686166

www.intechopen.com

\section{InTech China}

Unit 405, Office Block, Hotel Equatorial Shanghai

No.65, Yan An Road (West), Shanghai, 200040, China 中国上海市延安西路65号上海国际贵都大饭店办公楼405单元

Phone: +86-21-62489820

Fax: $+86-21-62489821$ 
(C) 2010 The Author(s). Licensee IntechOpen. This chapter is distributed under the terms of the Creative Commons Attribution-NonCommercialShareAlike-3.0 License, which permits use, distribution and reproduction for non-commercial purposes, provided the original is properly cited and derivative works building on this content are distributed under the same license. 